\title{
DESIGN OF A 3D PHYSICAL AND NUMERICAL EXPERIMENT ON FLOATING OFF-SHORE WIND TURBINES
}

\author{
Giuseppe Roberto Tomasicchio ${ }^{1}$, Elvira Armenio ${ }^{1}$, Felice D’Alessandro ${ }^{1}$, Nuno Fonseca ${ }^{2}$, \\ Spyros A. Mavrakos ${ }^{3}$, Valery Penchev ${ }^{4}$, Holger Schüttrumpf ${ }^{5}$, Spyridon Voutsinas ${ }^{6}$, Jens \\ Kirkegaard $^{7}$, Palle M. Jensen ${ }^{7}$
}

\begin{abstract}
The knowledge of the behavior of floating offshore wind turbines (W/T) under wave and/or wind action remains one of the most difficult challenges in offshore engineering which is mostly due to the highly non-linear response of the structure. The present study describes the design process of a 3D physical experiment to investigate the behavior of the most promising structure technology of floating W/T: spar buoy (SB) and tension leg platform (TLP) under different meteo conditions.

In order to properly design the two W/T models, the following topics have been analyzed: mooring lines, mass distribution, appropriate scaling factor and data relative to the geometrical characteristics, wave basin dimensions and wind and waves conditions.

In addition, the Smoothed Particle Hydrodynamics method (SPH) (Monaghan 1994) has been considered to simulate the 3D behavior of a floating offshore $\mathrm{W} / \mathrm{T}$. In particular, the $\mathrm{SPH}$, calibrated and verified on the basis of the experimental observations, may represent a reliable tool for preliminary test of changes in the floater geometry.
\end{abstract}

Keywords: floating wind turbines; tension leg platform; spar buoy; SPH

\section{INTRODUCTION}

Capabilities for predicting wind and wave loads on floating offshore wind turbines (W/T) have reached considerable interest in recent years; these structures represent both a great hope for renewable energies due to the wind resource potential available in deep water areas and a significant challenge for engineers and scientists. The determination of design loads on offshore floating W/T is a complex topic involving different wave and wind models, load-calculation methods and probability analysis.

While the fixed W/T technology can be considered mature, and many turbines have been installed in water depths up to around $25 \mathrm{~m}$, it is recognized that to reach the objectives of renewable energy production it will be necessary to expand the technology for deeper waters adopting a floater as a support structure for offshore W/T; above 40 to $50 \mathrm{~m}$ water depth it becomes economically advantageous to use a floater. However, the dynamic analysis of these structures is still an unsolved and complex problem due to the interactions between the W/T and the floater/mooring system. In several occasions, the challenges encountered in the analysis and design are increased due to the presence of the rotor and the complex action of the anchor chains retaining the floating body, which modify the dynamic response of the structure (Jonkman et al. 2009).

In the process of understanding the behavior of these complex structures, physical model tests are required, which represents another challenge by itself at any coastal and oceanographic laboratory, mostly due to the difficulties encountered in the instrumentation of the body and the evaluation of the

\footnotetext{
${ }^{1}$ Engineering Department, University of Salento, via Monteroni, Ecotekne, 73100 Lecce, Italy.

${ }^{2}$ Centre of Marine Technology and Engineering, Instituto Superior Técnico, Technical University of Lisbon, Av. Rovisco Pais, 1049- 001 Lisbon, Portugal.

${ }^{3}$ School of Naval Architecture and Marine Engineering, National Technical University of Athens, 9 Heroon Polytechniou Ave., 15773 Zografou, Athens, Greece.

${ }^{4}$ CORES (Coastal Research Engineering and Environmental Services), Business Incubator Asparuhovo, offices 212-213, 90023 Varna, Bulgaria.

${ }^{5}$ Institute of Hydraulic Engineering and Water Resources Management, RWTH, Aachen University, Mies-van-der-RoheStrasse 1, 52056 Aachen, Germany.

${ }^{6}$ School of Mechanical Engineering, National Technical University of Athens, 9 Heroon Polytechniou Ave., 15780 Zografou, Athens, Greece.

${ }^{7}$ Marine Technology Division, DHI Water \& Environment, Agern Allee 11, 2970 Hoersholm, Denmark.
} 
scale effects. Furthermore, numerical modeling of the hydrodynamic behavior remains an attractive analysis approach, yet it requires the application of highly complex and computer demanding models (e.g. SPH, Monaghan 1994, Hérault et al. 2010, Tomasicchio et al. 2011), which in turn need model scale and/or prototype measurements for calibration and validation (Lomonaco et al. 2010).

The present paper intends to describe the methodology adopted and the experience learned from the design of a physical experiment aiming to improve the understanding of the dynamic response of floating offshore W/T under combined wind and wave action at deep water conditions.

Different support platform configurations are possible for a floating offshore W/T. In particular, in the laboratory phase, the dynamic behavior and the stress conditions for the two main technologies of offshore W/T are investigated: the ballasted deep-drafted spar buoy (SB) and the unballasted tension leg platform (TLP) (Figure 1). The SB presents a long mast having approximately half of its length underwater; the mast has a counterweight at the deeper end and a floating device just below the free surface. The TLP presents a floating platform with steel lines tethered from its corners of the floating platform to concrete-blocks or other mooring systems lying at the ocean floor.

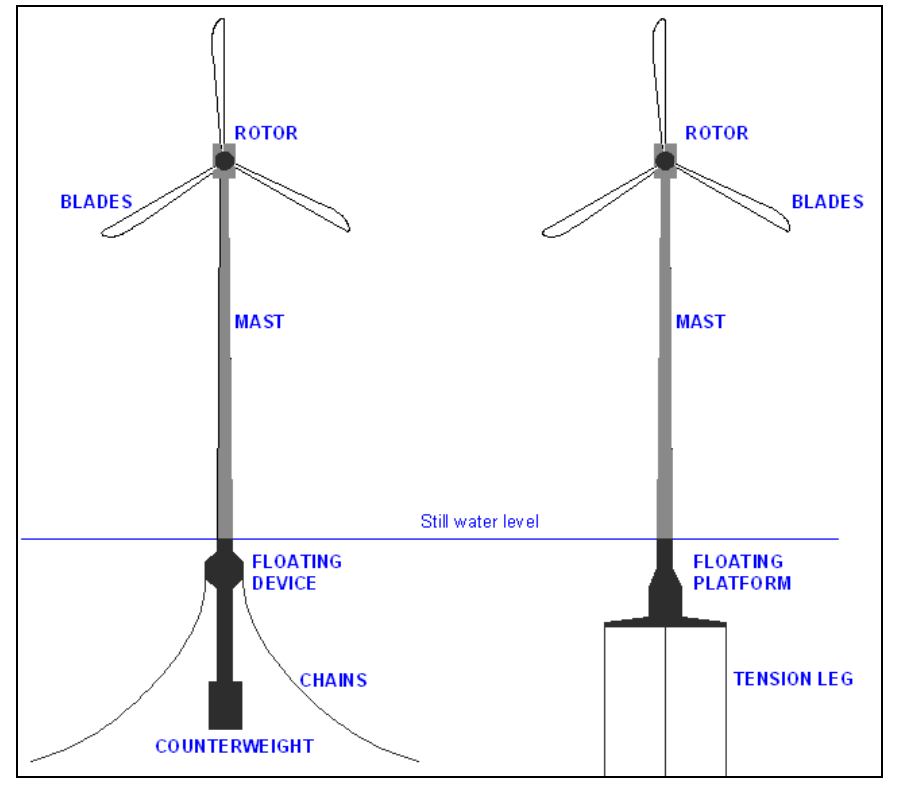

Figure 1. The floating W/T: spar buoy (SB) and tension leg platform (TLP).

\section{DESIGN OF THE PHYSICAL MODEL}

The main objective of the laboratory experiment is to investigate on natural frequency and on resonance conditions of the structure; to identify the effect of the anchor chains in the response of the floating body, including the measurement of the tensions along the chains; to study the hydrodynamic aspects of a floating $\mathrm{W} / \mathrm{T}$ and to create an accurate database for numerical models calibration and verification. In order to design two TLP and SB models, two prototypes have been taken as a reference: the MIT/NREL and the OC3-Hywind (Jonkman et al. 2009; Jonkman 2010). Table 1 summarizes the main characteristics of the two prototypes.

The MIT/NREL is a floating W/T from modifications to a TLP made at the Massachusetts Institute of Technology (MIT); it consists of a cylindrical platform, ballasted with concrete and moored by four pairs of vertical tendons in tension; each pair of tendons attaches to a spoke that radiates horizontally from the bottom of the platform; the concrete ballast is used to ensure that the combined turbine-platform system remains stable during float-out, even without the tendons, in mild metocean conditions.

The OC3-Hywind is a SB floating W/T developed within the Offshore Code Comparison Collaboration (OC3), which is a project operating under Subtask 2 of the International Energy Agency (IEA) Wind Task 23.1. The OC3-Hywind system imitates the SB concept called "Hywind," developed 
by Statoil Hydro of Norway; it features a deeply drafted, slender SB with three catenaries mooring lines. The lines attach to the platform via a delta connection (or "crowfoot") to increase the yaw stiffness of the moorings.

The MIT/NREL and the OC3-Hywind were specifically designed to support the rotor, nacelle, and tower of the "NREL5-MW system" which is a conventional three-bladed upwind variable-speed and variable blade-pitch-to-feather-controlled turbine. Table 2 summarizes some of its characteristics; more details are given in Jonkman et al. (2009).
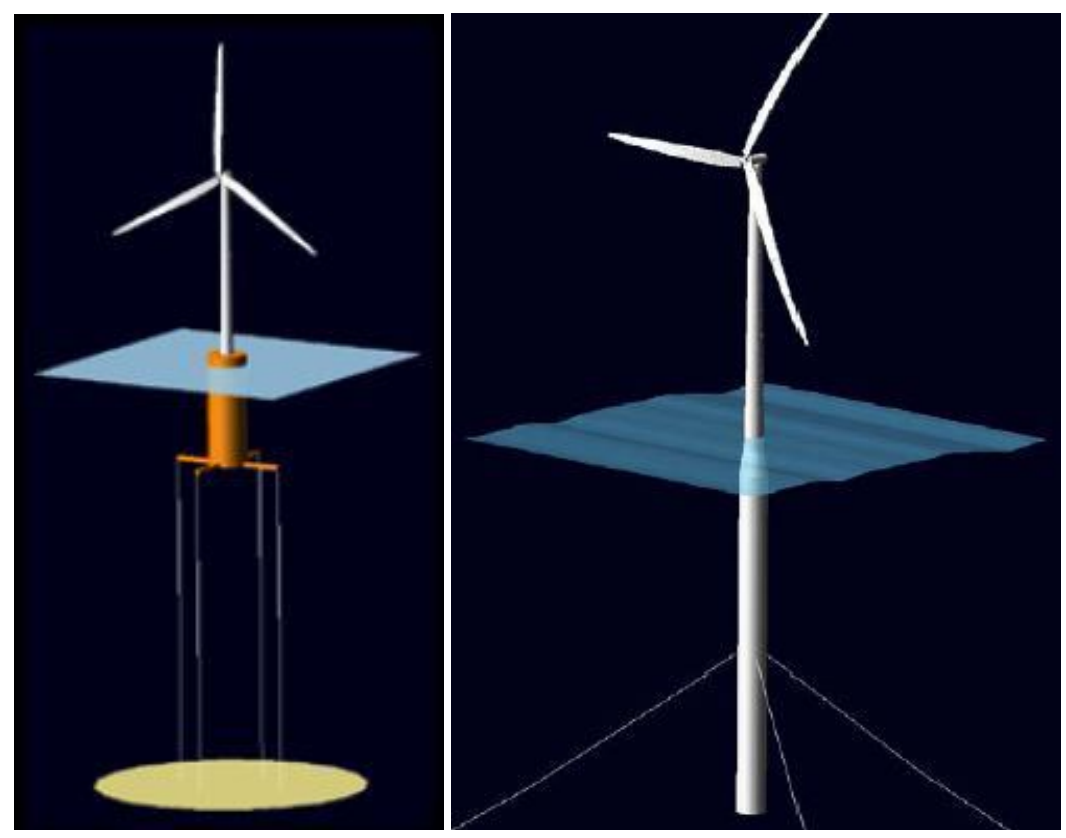

Figure 2. Reference prototypes: the MIT/NREL TLP (left) and the OC3-Hywind SB (right).

\begin{tabular}{|l|l|l|}
\hline \multicolumn{3}{|c|}{ Table 1. Summary of Properties of the two Floating Platform types (Jonkman and Matha 2009). } \\
\hline & MIT/NREL & HYWIND \\
\hline Diameter or width x length & $18 \mathrm{~m}$ & $6.5 \mathrm{~m}$ to $9.4 \mathrm{~m}$ (is tapered) \\
\hline Draft & $47.89 \mathrm{~m}$ & $120 \mathrm{~m}$ \\
\hline Water displacement & $12,180 \mathrm{~m}^{3}$ & $8,029 \mathrm{~m}^{3}$ \\
\hline Mass, including ballast & $8,600,000 \mathrm{~kg}$ & $7,466,000 \mathrm{~kg}$ \\
\hline CM location below still water level (SWL) & $40.61 \mathrm{~m}$ & $89.92 \mathrm{~m}$ \\
\hline Roll inertia about CM & $571,600,000 \mathrm{~kg}^{*} \mathrm{~m}^{2}$ & $4,229,000,000 \mathrm{~kg}^{*} \mathrm{~m}^{2}$ \\
\hline Pitch inertia about CM & $571,600,000 \mathrm{~kg}^{*} \mathrm{~m}^{2}$ & $4,229,000,000 \mathrm{~kg}^{*} \mathrm{~m}^{2}$ \\
\hline Yaw inertia about CM & $361,400,000 \mathrm{~kg}^{*} \mathrm{~m}^{2}$ & $164,200,000 \mathrm{~kg}^{*} \mathrm{~m}^{2}$ \\
\hline Number of mooring lines & $8(4 \mathrm{pairs})$ & 3 \\
\hline Depth to fairleads, anchors & $47.89 \mathrm{~m}, 200 \mathrm{~m}$ & $5.2 \mathrm{~m}, 853.9 \mathrm{~m}$ \\
\hline Radius to fairleads, anchors & $27 \mathrm{~m}, 27 \mathrm{~m}$ & $70 \mathrm{~m}, 320 \mathrm{~m}$ \\
\hline Unstreached line length & $151.7 \mathrm{~m}$ & $902.2 \mathrm{~m}$ \\
\hline Line diameter & $0.127 \mathrm{~m}$ & $0.09 \mathrm{~m}$ \\
\hline Line mass density & $116 \mathrm{~kg} / \mathrm{m}$ & $77.71 \mathrm{~kg} / \mathrm{m}$ \\
\hline Line extensional stiffness & $1,500,000,000 \mathrm{~N}$ & $384,200,000 \mathrm{~N}$ \\
\hline
\end{tabular}




\begin{tabular}{|l|l|}
\hline \multicolumn{2}{|c|}{$\begin{array}{c}\text { Table 2. Summary of Properties for the NREL 5-MW Baseline Wind } \\
\text { Turbine (Jonkman and Matha 2009). }\end{array}$} \\
\hline Rating & $5 \mathrm{MW}$ \\
\hline Rotor orientation, configuration & Upwind, 3 blades \\
\hline Control & Variable speed, collective pitch \\
\hline Driventrain & High speed, multiple-stage gearbox \\
\hline Rotor, hub diameter & $126 \mathrm{~m}, 3 \mathrm{~m}$ \\
\hline Hub height & $90 \mathrm{~m}$ \\
\hline cut-in, rated, cut-out wind speed & $3 \mathrm{~m} / \mathrm{s}, 11.4 \mathrm{~m} / \mathrm{s}, 25 \mathrm{~m} / \mathrm{s}$ \\
\hline cut-in, rated rotor speed & $6.9 \mathrm{rpm}, 12.1 \mathrm{rpm}$ \\
\hline Rated tip speed & $80 \mathrm{~m} / \mathrm{s}$ \\
\hline Overhang, shaft tilt, precone & $5 \mathrm{~m}, 5^{\circ}, 2.5^{\circ}$ \\
\hline Rotor mass & $110,000 \mathrm{~kg}$ \\
\hline Nacelle mass & $240,000 \mathrm{~kg}$ \\
\hline Tower mass & $347,500 \mathrm{~kg}$ \\
\hline $\begin{array}{l}\text { Coordinate location of overall center of } \\
\text { mass (CM) }\end{array}$ & $(-0.2 \mathrm{~m}, 0.0 \mathrm{~m}, 64.0 \mathrm{~m})$ \\
\hline
\end{tabular}

\section{Offshore wave basin}

The experiments are performed at the DHI Offshore Wave Basin (DK). The wave basin is $20 \mathrm{~m}$ long and $30 \mathrm{~m}$ wide with an overall water depth of $3 \mathrm{~m}$ and a $5 \mathrm{~m}$ pit (Figure 3). The wave basin is equipped with 60 individually controlled flaps capable of generating regular and irregular waves attacks. A parabolic wave absorber located opposite the wave maker minimizes reflection.

Waves are generated with mean directions of wave fronts until $+/-25$ degrees. Wind load on W/T is simulated by computer controlled wind fans. In particular, wind are generated perpendicular to the wave maker with velocity up to $2 \mathrm{~m} / \mathrm{s}$. The values of wind speed range between 0 and $27 \mathrm{~m} / \mathrm{s}$; the values of significant wave height range between $0.03 \mathrm{~m}$ and $0.45 \mathrm{~m}$; the values of the wave period range between $0.5 \mathrm{~s}$ and $5.0 \mathrm{~s}$.

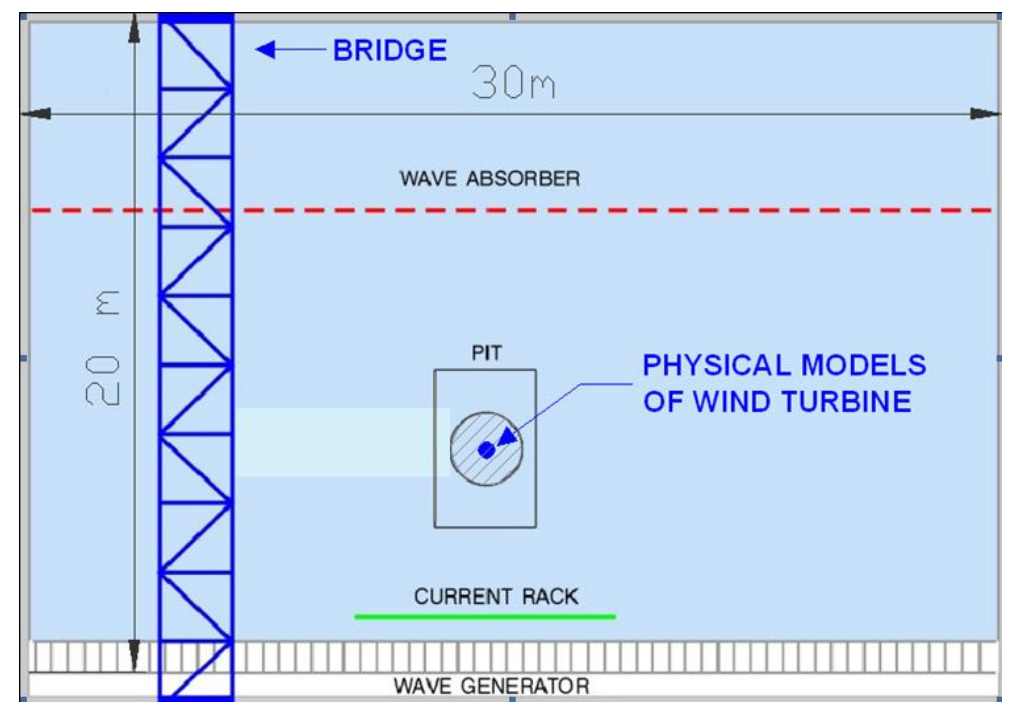

Figure 3. Offshore Wave Basin at DHI.

\section{Models characteristics: materials and mass distribution}

In order to properly simulate the dynamic behavior of a floating W/T subjected to aerodynamic and hydrodynamic loading a 1:40 scale factor has been chosen; data relative to the geometrical 
characteristics, the centre of gravity, the mass distribution have been selected with regard to the basin dimensions and the wave and wind reproducible conditions.

The floater and the tower of the two physical models are made of plastic material and the legs of aluminium. An internal mast is used to fix the 4 legs at the base of the floater.

The tower in the OC3- Hywind prototype has a tapered shape: the lower diameter is $6.5 \mathrm{~m}$ and the upper diameter is $3.8 \mathrm{~m}$ (Jonkman 2010).

The model blades have been designed in accordance to the prototypes conditions; it results that each of the three blades is $1.5 \mathrm{~m}$ long and $240 \mathrm{~g}$ weighing. The rotor mass is $45 \mathrm{~g}$ and $300 \mathrm{~mm}$ diameter; it is driven by an electric motor and it is responsible for the gyroscopic effect. The wind load is generated perpendicular to the wave generator by a fun which provides a thrust of $10-12 \mathrm{~N}$ at 7400 rpm.

\section{The gyroscopic effect}

The angular velocity of the rotor combined with the yaw velocity produces a pitch moment (and similarly when combined with pitch it produces a yaw moment). The gyroscopic moment is given by:

$$
M^{g y r}=I^{R} \omega \cdot \Omega
$$

where $I^{R}$ is the moment of inertia of the rotor about the axis of rotation, $\omega$ is the angular velocity of the rotor and $\Omega$ is the angular velocity of yaw. The relation between the induced moments at the model scale and full scale is:

$$
M_{m}^{g y r}=M_{F S}^{g y r} \frac{1}{s^{4}}
$$

where $s$ is the scale factor (the subscript $m$ and $F S$ stand respectively for model scale and full scale).

From the point of view of the gyroscopic effects, only the gyroscopic moment needs to be scaled down from full scale to model scale. This has been achieved by adjusting the inertia of the rotor about the axis of rotation and/or the angular velocity of the rotor. However, the moment of inertia of the rotor about the three axis of coordinate system should be properly scaled down to obtain similarity of the inertial forces because they influence the roll, pitch and yaw motions. Therefore, it has been assumed that the moment of inertia of the rotor at the model scale is:

$$
I_{m}^{R}=\frac{I_{F S}^{R}}{S^{5}}
$$

and the rotor angular velocity and the yaw velocity are:

$$
\begin{gathered}
\omega_{m}=\omega_{F S} \sqrt{s} \\
\Omega_{m}=\Omega_{F S} \sqrt{s}
\end{gathered}
$$

Substituting Eq.s (3), (4), and (5), in Eq.(2):

$$
M_{m}^{g y r}=\frac{I_{F S}^{R}}{s^{5}} \cdot \omega_{F S} \sqrt{s} \cdot \Omega_{F S} \sqrt{s}
$$

Assuming that the gyration radius of the rotor is $\mathrm{D} / 4$ ( $\mathrm{D}$ is the diameter) and given the rotor mass of $45 \mathrm{~g}$ and $\mathrm{rpm}$ of 7400 , the induced moment is: 


$$
M_{g y r}=0.196 \cdot \Omega
$$

where $\Omega$ is the angular velocity of yaw, or pitch.

For a comparison, taking the data from the NREL 5MW turbine (Jonkman et al. 2009), including the rotor and hub, and scaling down to the model scale, the gyroscopic moment of the turbine is:

$$
M_{g y r}=2.783 \cdot \Omega
$$

\section{DESIGN OF SB AND TLP MOORING LINES}

\section{SB model}

As in Jonkman (2010), the SB prototype is composed by 3 mooring lines (Table 3), each of which has a length of $902.2 \mathrm{~m}$ and a submerged weight per unit length equal to $698.094 \mathrm{~N} / \mathrm{m}$.

The water depth is assumed equal to $320 \mathrm{~m}$, the attachment points of the top of the lines on the buoy are assumed at $70 \mathrm{~m}$ below the SWL: the vertical distance between the attachment points and the sea bottom is $250 \mathrm{~m}$; the azimuthal angles between two adjacent mooring lines are equal to 120 degrees.

\begin{tabular}{|l|l|}
\hline \multicolumn{2}{|c|}{ Table 3. Mooring lines properties of the SB prototype. } \\
\hline Number of Mooring Lines & 3 \\
\hline Angle Between Adjacent Lines & $120^{\circ}$ \\
\hline Depth to Anchors Below SWL (Water Depth) & $320 \mathrm{~m}$ \\
\hline Depth to Fairleads Below SWL & $70.0 \mathrm{~m}$ \\
\hline Radius to Anchors from Platform Centerline & $853.87 \mathrm{~m}$ \\
\hline Vertical distance from fairleads to sea bottom & $250 \mathrm{~m}$ \\
\hline Radius to Fairleads from Platform Centerline & $5.2 \mathrm{~m}$ \\
\hline Unstretched Mooring Line Length & $902.2 \mathrm{~m}$ \\
\hline Mooring Line Diameter & $0.09 \mathrm{~m}$ \\
\hline Equivalent Mooring Line Mass Density & $77.7066 \mathrm{~kg} / \mathrm{m}$ \\
\hline Equivalent Mooring Line Weight in Water & $698.094 \mathrm{~N} / \mathrm{m}$ \\
\hline Equivalent Mooring Line Extensional Stiffness & $384,243,000 \mathrm{~N}$ \\
\hline Additional Yaw Spring Stiffness & $98,340,000 \mathrm{Nm} / \mathrm{rad}$ \\
\hline
\end{tabular}

In the design of the SB model, a single mooring static analysis has been performed to obtain the initial fairlead angles and to determine the locations where to set the anchor plates. The analysis has been done by the code STATMOOR (Mavrakos 1992) which is capable to handle the static analysis of extensible mooring lines made of several segments each of them with different geometrical properties and with attached submerged buoys along them. The equilibrium position has been identified and the corresponding horizontal force component at the upper end (fairlead) has been determined.

According to Jonkman (2010), the total vertical component of the force that the buoy experiences from the three mooring lines is $1,607,000 \mathrm{~N}$, i.e. $V=535,667 \mathrm{~N}$ vertical force per line. Being the vertical component of the force known and considering the submerged weight of the line per unit length, $w$, given in Table 3, i.e. $w=698.094 \mathrm{~N} / \mathrm{m}$, it is possible to evaluate the suspended mooring line length $l_{s}$, (for the in-extensible cable case):

$$
l_{s}=\frac{V}{w}=\frac{535667 \mathrm{~N}}{698.094 \mathrm{~N} / \mathrm{m}}=767.33 \mathrm{~m}
$$

Considering the vertical distance of the fairleads to the sea bottom, $D$, the horizontal force at the top is then given by: 


$$
H=\frac{w\left(l_{s}^{2}-D^{2}\right)}{2 D}=734800 \mathrm{~N}
$$

whereas the projection of the suspended mooring line length on the horizontal direction is obtained by:

$x=\frac{H}{w} \cosh ^{-1}\left(\frac{w D}{H}+1\right)=\frac{734800}{698.094} \cosh ^{-1}\left(\frac{698.094 \cdot 250}{734800}+1\right)=711.817 m$

and the distance from the anchor, $x_{A}$, is:

$$
x_{A}=l-l_{s}+x=902.2-767.3+711.8 \cong 846.7 \mathrm{~m}
$$

By inserting the value of the horizontal force as input to the code STATMOOR (Mavrakos 1992), the static configuration at the equilibrium position of the single mooring line has been obtained together with the vertical component of the force at the top, the corresponding angle at the top and along the line, as well as the horizontal distance of the top of the line from the anchor.

In Figure 4, the static shape of the single mooring line is depicted for various horizontal forces applied the line's top end. The horizontal force value case of $0.73 \mathrm{E} 6 \mathrm{~N}$ is very close to the actual static equilibrium position of the mooring line, whereas for the highest selected horizontal force the whole mooring line has been lifted from the bottom forming a zero angle with it. A number of horizontal forces lower that the one corresponding to the equilibrium position has been investigated too, in order to have a comprehensive understanding of the mooring line behavior for positive and negative displacements of the fairlead with respect to its equilibrium position.

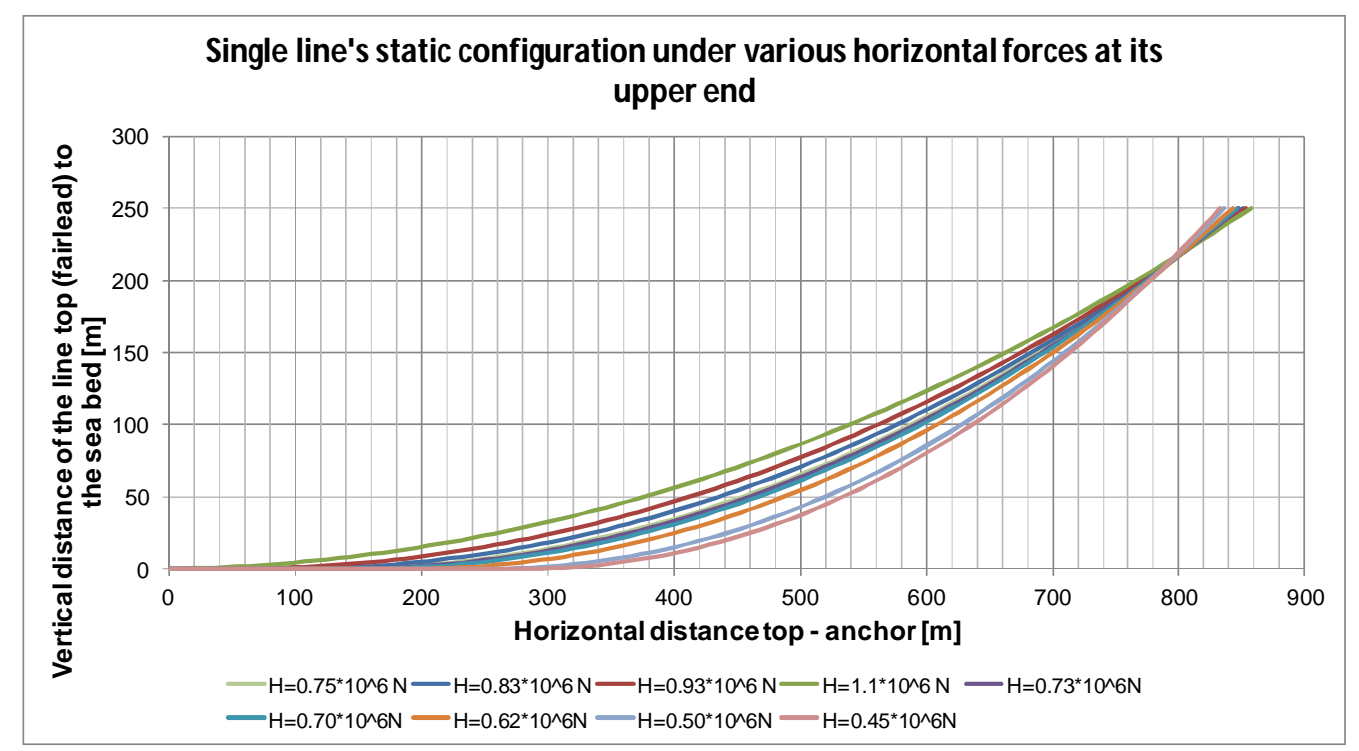

Figure 4. Static configuration of the single mooring line for several horizontal forces applied at its upper end (fairlead).

It has been observed that by accounting for the elasticity of the mooring line, a slight deviation from the above values at the equilibrium position appears. So, the distance of the fairlead from the anchor at the equilibrium position is $847 \mathrm{~m}$ with an amount of chain lying on the sea bottom equal to approximately $134 \mathrm{~m}$. 
In Figure 5 the angle between the line's upper end and the horizontal direction is given as a function of the horizontal distance of the fairlead to the anchor. The lowest horizontal excursion of the fairlead to the anchor corresponds to the equilibrium position.

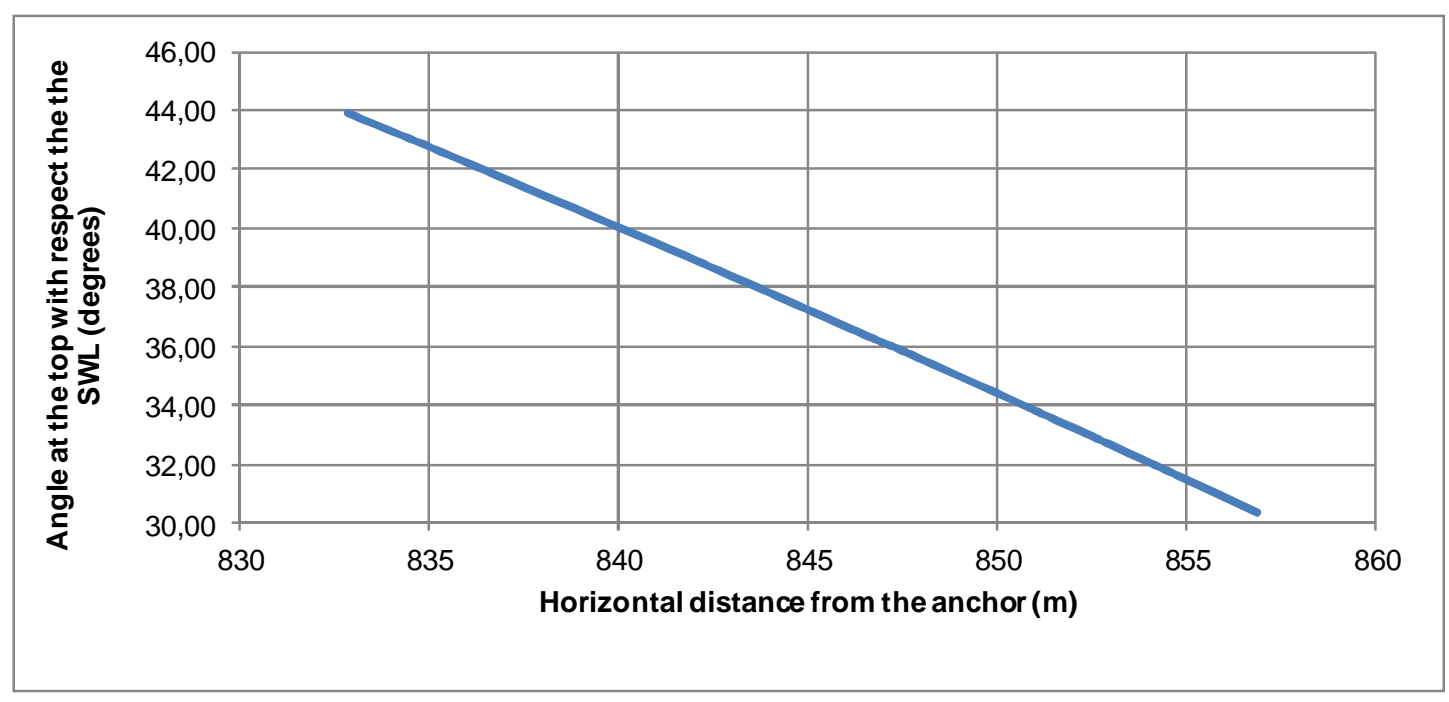

Figure 5. The angle between the line's upper end and the horizontal is given as a function of the horizontal distance of the fairlead to the anchor.

\section{TLP model}

The value of "line extensional stiffness" of the MIT/NREL prototype is 1,500,000,000 N (Table 1) which corresponds to $E^{*} A$ ( $E$ is the Young's modulus of elasticity and $A$ is the cross sectional area of the cable).

By accounting that $\sigma=\mathrm{E}^{*} \varepsilon$ or, equivalently:

$$
\frac{T}{A}=E \frac{\Delta l}{l} \Rightarrow \frac{T}{\Delta l}=\frac{E A}{l} \Rightarrow k_{\text {extensional }}=\frac{E A}{l}
$$

with $T$ being the tension at the top of the line and $l$ is the unstretched line length of the mooring line for the TLP prototype.

Referring to Matha (2009) and Jonkman et al. (2009), the unstretched line length of the TLP prototype results $151.7 \mathrm{~m}$ (Table 1), and applying Eq.(13), the value of the equivalent mooring line extensional stiffness, $k_{\text {extensiona }}$ is obtained; it represents the extensional stiffness of the mooring line for a line $1 \mathrm{~m}$ long.

$$
k_{\text {extensiond }}=\frac{E A}{l}=\frac{1.5 \cdot 10^{9} \mathrm{~N}}{151.7 \mathrm{~m}}=988,8 \cdot 10^{4} \frac{\mathrm{N}}{\mathrm{m}} \approx 10000 \frac{\mathrm{kN}}{\mathrm{m}}
$$

In the design process of the physical model, given the values of $K_{\text {extensional }}$ and $l$ (Table 1 ), by means of Eq. (14), the value of $E^{*} A$ has been obtained and afterward the value of $d$ determined.

\section{INSTRUMENTS}

Wave gauges together with a 3D acoustic anemometer are used to measure incident/reflected waves combined with wind action; accelerometers and load cells are placed along the mast and the anchor chains. Flow velocity components at different points of the prototype are also sampled. 
The forces at the tower toe are measured by means of a force meter (6DOF force gauge) designed at DHI; it is mounted at the link between the foundation and the tower (Figure 6) and at $25 \mathrm{~cm}$ above the still water level. The geometrical characteristics of the force block are:

- $\quad$ base of 95 x $95 \mathrm{~mm}$;

- $\quad$ height of $140 \mathrm{~mm}$.

The maximum values of force components and moments along the axis are:

$$
\begin{array}{ll}
- & \mathrm{Fx}=\mathrm{Fy}=\mathrm{Fz}=350 \mathrm{~N} ; \\
- & \mathrm{Mx}=\mathrm{My}=355 \mathrm{Nm} ; \\
- & \mathrm{Mz}=20 \mathrm{Nm} .
\end{array}
$$

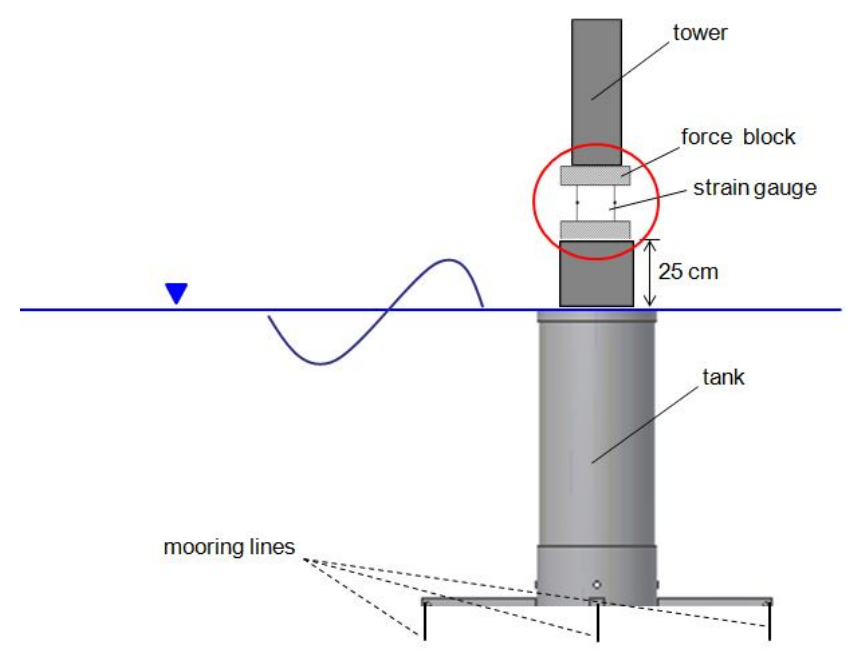

Figure 6. 6DOF force gauge.

The time variation of the pressure distribution is observed by means of transducers displaced as in Figure 7.

TLP type

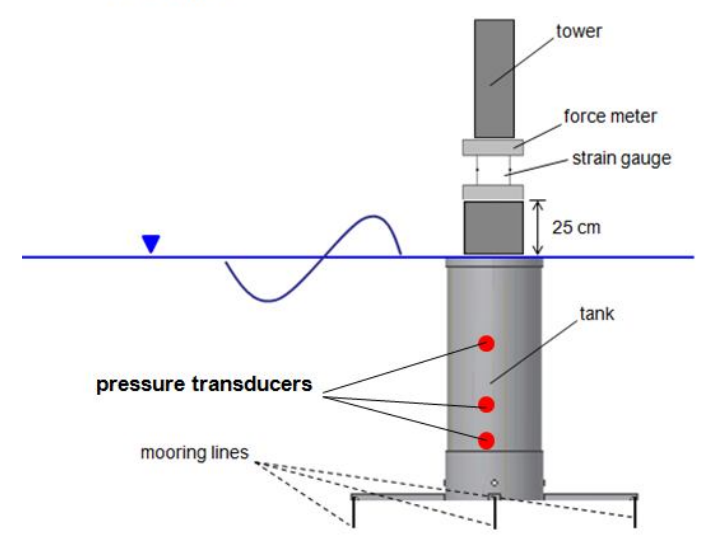

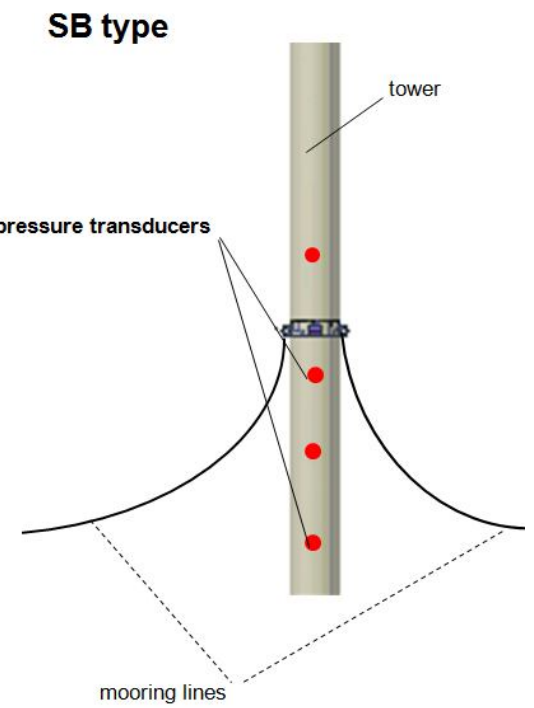

Figure 7. Pressure transducers. 
Motions of the floating model is measured by the DHI Marine Track system, a video-based tracking system capable of capturing 6DOF motions pointing at 2 balls fixed at the structure; a fast speed camera is also used to record wave breaking and slamming effects (Figure 8).
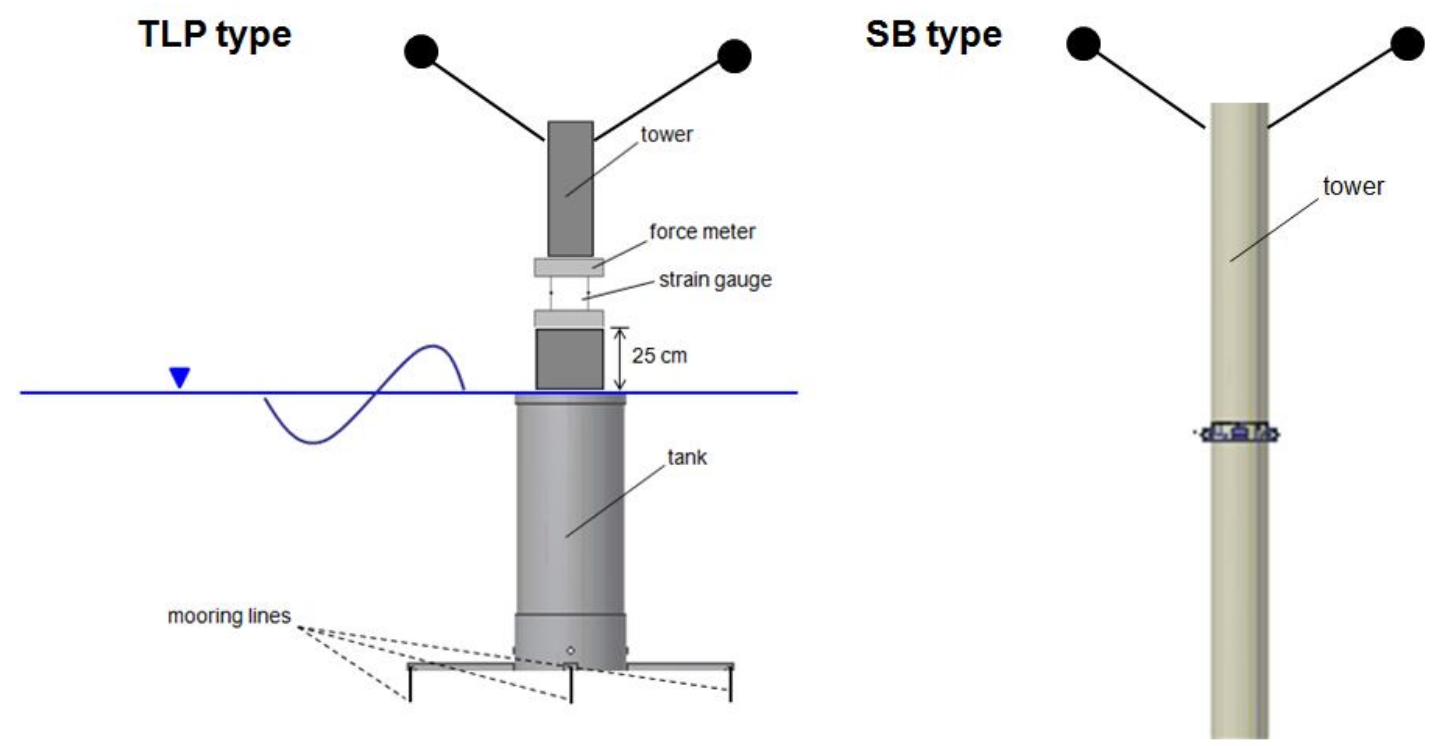

Figure 8. DHI Marine Track system.

\section{Test program}

A number of test series are performed by simulating three basic different meteo conditions:

-C1 "no wind" condition refers to the case where the dynamics of the floating turbine is to be studied under waves only;

-C2 "operational conditions" means that the rotor blades rotate and the turbine generates electricity. This corresponds to full-scale wind speeds from $3 \mathrm{~m} / \mathrm{s}$ (cut-in) to $25 \mathrm{~m} / \mathrm{s}$ (cutoff), as for the NREL 5MW reference turbine. Rated wind velocity for $5 \mathrm{MW}$ NREL turbine is $11.4 \mathrm{~m} / \mathrm{s}$;

-C3 "extreme conditions" refers to survival tests, with extreme wind and wave conditions (1/50 years). The rotor is stopped.

\section{HYDRODYNAMIC MODEL}

The experimental results are adopted to assess and validate the Smoothed Particle Hydrodynamics (SPH) technique (Monaghan 1994, Hérault et al. 2010) in simulating, in a near-field approach, the problem of the wave impact on a moored offshore floating structure.

The development of SPH is well documented (Dalrymple and Rogers 2006). The mathematical basis for the SPH method is modeling the fluid domain as a number of discrete particles whose interactions are based on the Navier-Stokes equations. The advantages of SPH arise directly from its Lagrangian nature, since a Lagrangian approach can tackle difficulties related with lack of symmetry or a multiply-connected fluid much more efficiently than Eulerian methods can. There are no constraints imposed either on the geometry of the system or in how far it may evolve from the initial conditions.

In the present study, an SPH based code called DualSPHysics (www.sphysics.org) has been used to simulate a floating wind turbine undergoing regular waves. DualSPHysics is a part of the SPHysics Project developed by Univeristy of Vigo, University of Manchester and Johns Hopkins University; it is implemented in $\mathrm{C}++$ and CUDA language to carry out simulations on GPU allowing to simulate reallife engineering problems (Crespo et al. 2011). 
The offshore wave basin has been described as a $3 \mathrm{D}$ rectangular box with a wavemaker piston type. Particle associated to the wavemaker move following a sinusoidal movement with amplitude equal to $0.15 \mathrm{~m}$, wave period of $2 \mathrm{~s}$ and duration equal to $5 \mathrm{~s}$. The Wendland Kernel function and the Symplectic algorithm time stepping have been applied.

A 3D CAD software has been used to draw in a more realistic way the floating structure. The wind turbine-object has been imported in the numerical code and converted into particles, exactly it was composed of solid boundary particles; for each particle, the local position is fixed relative to each other and their global positioning dependent on the hydrodynamic forcing of the water waves which act to the obstacle surface.

Once an initial geometry is defined, the particles that have been created in the numerical domain are characterized with scalar parameters that include mass, pressure, and velocity components. The values of these properties for all the particles are interpolated to compute any of the scalar quantities at each particle, using a smoothing function that is known as the Kernel function.

Figure 9 shows three snapshots $(\mathrm{t}=0 \mathrm{~s} ; \mathrm{t}=2 \mathrm{~s} ; \mathrm{t}=5 \mathrm{~s})$; at $\mathrm{t}=0$, the wind turbine object is floating but shortly after, at time step $12(\mathrm{t}=5 \mathrm{~s})$, the structure is overturned because the effect of mooring lines has not yet been implemented in the code.

Preliminary runs demonstrate that SPH can simulate the interaction of a fluid with a floating object.

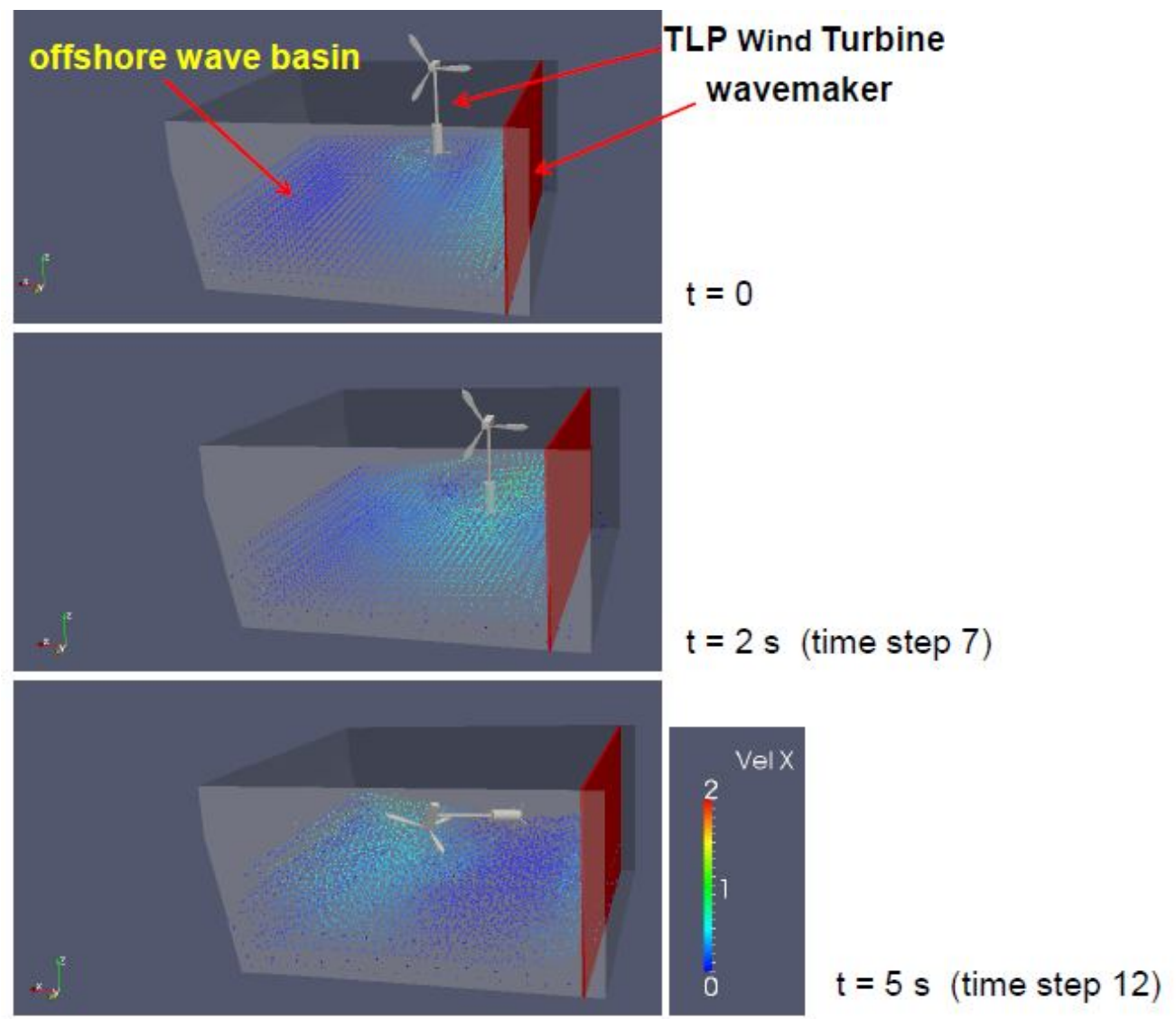

Figure 9. Simulation of a floating object by using an SPH based code.

\section{CONCLUSIONS}

The present paper describes the design process of a 3D physical experiment for the most promising structure technologies of floating W/T: spar buoy and tension leg platform.

For the design of the SB model, a single mooring static analysis has been performed to obtain the initial fairlead angles and to determine the locations where to set the anchor plates; the equilibrium 
position and the corresponding horizontal force component at the upper end (fairlead) has been also determined; the equivalent mooring line extensional stiffness and the unstretched line length have been used to evaluate the diameter of the mooring line for both TLP and SB models.

An analysis of the gyroscopic moment induced by the fan has been conducted and the relation between the induced moments at the model scale and at full scale has been obtained to evaluate the gyroscopic effect produced in the physical model.

Finally, a numerical model has been set-up for simulating a floating W/T by adopting the Smoothed Particle Hydrodynamic (SPH) method (Monaghan 1994). The dynamic analysis of a floating W/T response under the wave and wind forcing involves complex aspects related with fluidstructure interaction; in this context it is shown that the adoption of a SPH technique to overcome the linear potential-flow theory seems to offer promising results as its lagrangian approach, along with the assumption of a meshless interpolant scheme, allows to adapt to possible high strains experienced by the fluid and the floating body; even surface separation is allowed, thus overcoming most of the critical aspects of other numerical techniques traditionally adopted for modeling the above mentioned problem.

\section{ACKNOWLEDGMENTS}

The present research is supported by the European Community's Seventh Framework Programme (FP7) through the grant to the budget of the Integrated Infrastructure Initiative HYDRALAB IV (Contract Number: 261520) within the Transnational Access Activities.

\section{REFERENCES}

Crespo, A.J.C., Dominguez, J.M., Barreiro, A., Gómez-Gesteira, M., Rogers, B.D., 2011. GPUs, a new tool of acceleration in CFD: Efficiency and reliability on Smoothed Particle Hydrodynamics methods. PLoS ONE. doi:10.1371/journal.pone.0020685.

Dalrymple, R.A., Rogers, B.D. 2006. Numerical modeling of water waves with the SPH method. Journal of Coastal Engineering, 53, 141 - 147.

Gomez-Gesteira, M., Dalrymple, R.A., 2004. Using a 3D SPH method for wave impact on a tall structure. Journal of Waterway, Port, Coastal, and Ocean Engineering, 130 (2), 63- 69.

Gómez-Gesteira, M., Rogers, B.D., Crespo, A.J.C., Dalrymple, R.A., Narayanaswamy, M., Dominguez, J.M., 2012a. SPHysics - development of a free-surface fluid solver- Part 1: Theory and Formulations. Computers \& Geosciences, doi:10.1016/j.cageo.2012.02.029.

Gómez-Gesteira, M., Crespo, A.J.C., Rogers, B.D., Dalrymple, R.A., Dominguez, J.M., Barreiro, A. 2012b. SPHysics - development of a free-surface fluid solver- Part 2: Efficiency and test cases. Computers \& Geosciences, doi:10.1016/j.cageo.2012.02.028.

Hérault, A., Bilotta, G., Dalrymple, R.A. 2010. SPH on GPU with CUDA. Journal of Hydraulic Research, 48 (Extra Issue), 74-79.

Jonkman, J., Matha, D. 2009. A quantitative comparison of the responses of three floating platform. Proceedings of European Offshore Wind 2009 Conference and Exhibition, NREL/CP-500-46726.

Jonkman, J., Butterfield, S., Musial, W., Scott G. 2009. Definition of a 5-MW Reference Wind Turbine for Offshore System Development. Technical Report NREL/TP-500-38060.

Jonkman, J. 2010. Definition of the floating system for phase IV of OC3, Technical Report NREL/TP500-47535.

Lomonaco, P., Guanche, R., Vidal, C., Losada, I.J., Migoya, L. (2010). Measuring and modelling the behaviour of floating slender bodies under wind and wave action. Proceedings of the International Conference Coastlab 10, Barcelona, paper n. 54.

Manenti, S., Panizzo A., Ruol P., Martinelli, L. 2008. SPH simulation of a floating body forced by regular waves. Proceedings of 3rd SPHERIC Workshop, pp. 38-41.

Mavrakos, S.A. 1992. STATMOOR User's manual, Laboratory for Floating Stuctures and Mooring Systems, School of Naval Architecture and Marine Engineering, National Technical University of Athens.

Matha, D. 2009. Model Development and Loads Analysis of an Offshore Wind Turbine on a Tension Leg Platform, with a Comparison to Other Floating Turbine Concepts. Technical Report NREL/SR-500-45891. 
Monaghan J.J., 1994. Simulating free surface flows with SPH. Journal of Computational Physics. Vol. 110, 399-406.

Monaghan, J.J., 2003. New developments in smoothed particle hydrodynamics, Meshfree Methods for Partial Differential Equations, Springer-Verlag, Heidelberg Germany, pp. 281-290.

Rudman, M. and Cleary, P.W. 2009. Using Smoothed Particle Hydrodynamics to study wave impact on floating off-shore platforms: the effect of mooring system. Proceedings of Seventh International Conferbence on CFD in the Minerals and Process Industries CSIRO, Melbourne, Australia.

Tomasicchio, G.R., D’Alessandro, F., Barbaro, G. 2011. Composite modelling for large scale experiments on wave-dune interactions. Journal of Hydraulic Research, Vol.49, No.S1, pp.15-19. 